\title{
Evidence for tidal triggering for the earthquakes of the Ionian geological zone, Greece
}

\author{
Michael E. Contadakis ${ }^{1, \star}$, Dimitrios N. Arabelos ${ }^{1}$, Spyrous D. Spatalas ${ }^{1}$
}

${ }^{1}$ Aristotle University of Thessaloniki, Department of Geodesy and Surveying, Thessaloniki, Greece

Article history

Received July 15, 2011; accepted November 7, 2011.

Subject classification:

Seismic risk, Lunisolar tides, Seismicity.

\begin{abstract}
We here investigate the evidence for tidal triggering of the earthquakes of the seismic area of the Ionian geological zone in Greece, using the cumulative histogram method that was introduced recently by Cadicheanu et al. (Nat. Hazards Earth Syst. Sci., 2007, 7, 733-740). We analyzed the series of earthquakes that occurred in the area bounded by $19^{\circ} \mathrm{E} \leq \varphi \leq 22^{\circ} \mathrm{E}$ and $36^{\circ} \mathrm{N} \leq \lambda \leq 40^{\circ} \mathrm{N}$ from 1964 to 2006. Over this time, there were 19.916 shallow and intermediate depth earthquakes with magnitudes ranging between 2.5 and 6.2. The great majority of these earthquakes, including those with $M \geq 5.0$, were shallow. The results of our analysis indicate that the monthly variations in the frequencies of the earthquake occurrence are in agreement with the period of the tidal lunar monthly variations. The same is true for the corresponding daily variations of the frequencies of earthquake occurrence and the diurnal lunisolar (K1) and semidiurnal lunar (M2) tidal variations. In addition, the confidence levels for the identification of such periodical agreement between the frequency of earthquake occurrence and the tidal periods varies according to the seismic activity; i.e. the higher confidence levels correspond to the periods with stronger seismic activity. These results are in favor of a tidal triggering process of earthquakes when the stress in the focal area is near the critical level.
\end{abstract}

\section{Introduction}

The question of possible connections between the Earth tides and earthquake occurrence is a very old one, and it has been tackled in a number of studies since more than 100 years ago. The results have been contradictory, with most of the outcomes not able to prove the possibility of any correlations between earthquake occurrence and the Earth tides [see for instance: Schuster 1897, Knopoff 1964, Simpson 1967, Shudde and Barr 1977, Rydelek et al. 1992, Vidale et al. 1998, and many others]. On the other hand, the outcomes of a considerable number of relatively recent studies have been in favor of such a correlation [see for instance: Enescu and Enescu 1999, Stavinschi and Souchay 2003, Tanaka et al. 2002, 2006, Cadicheanu et al. 2007 and many others).

Nevertheless, although the stress drop in an earthquake event is two or three orders higher than the amplitude of the tidal stress variations, the tidal stress rate is comparable or much higher than the tectonic stress accumulation in a fault. Thus, unless the earthquake event is the result of sudden stress accumulation on a fault [Vidale et al. 1998], it has to be concluded that the Earth tides can act as a triggering mechanism for a mature fault; i.e. a fault for which the stress accumulation is approaching the critical point for rupture occurrence. Recent analyses indicate that this is so [Tanaka et al. 2002, 2006, Cadicheanu 2007]. In these previous studies, not only was tidal triggering at the global [Tanaka et al. 2002] and local [Tanaka et al. 2006, Cadicheanu 2007] scales found, but in addition, in the last two studies, an increase in the reliability of the tidal-earthquake occurrence correlation was shown to be a precursory phenomenon for strong earthquakes.

In the present study, we statistically analyzed a sample of 19.916 shallow- and intermediate-depth earthquakes with magnitudes ranging from 2.5 to 6.2 that occurred in the Ionian Sea, with the purpose of investigating potential tidal triggering effects on earthquake occurrence.

\section{The data}

The dataset consists of a series of 19.916 earthquakes with local magnitude of $\mathrm{M}>2.5$ that occurred within the time interval from January 1964 to December 2006, in an area bounded by $19^{\circ} \mathrm{E} \leq \varphi \leq 22^{\circ} \mathrm{E}$ and $36^{\circ} \mathrm{N} \leq \lambda \leq 40^{\circ} \mathrm{N}$. The magnitudes were obtained from the Catalogue of the Geodynamic Institute of the National Observatory of Athens, Greece (http:/ / www.gein.noa.gr/services/ cat.html) Figure 1 is reproduced from Papazachos et al. [1998] and it shows the main morphotectonic characteristics, while Figure 2 is reproduced from Papazachos et al. [1999] and it shows the main faulting zones and faulting types in this area of Greece. The area under study lies along the western part of the Hellenic Trench. The faults in the area were directed parallel to the Hellenic Trench and represent thrust 




Figure 1. The main morphotectonic characteristics of the broader area of Greece [after Papazacos et al. 1998].

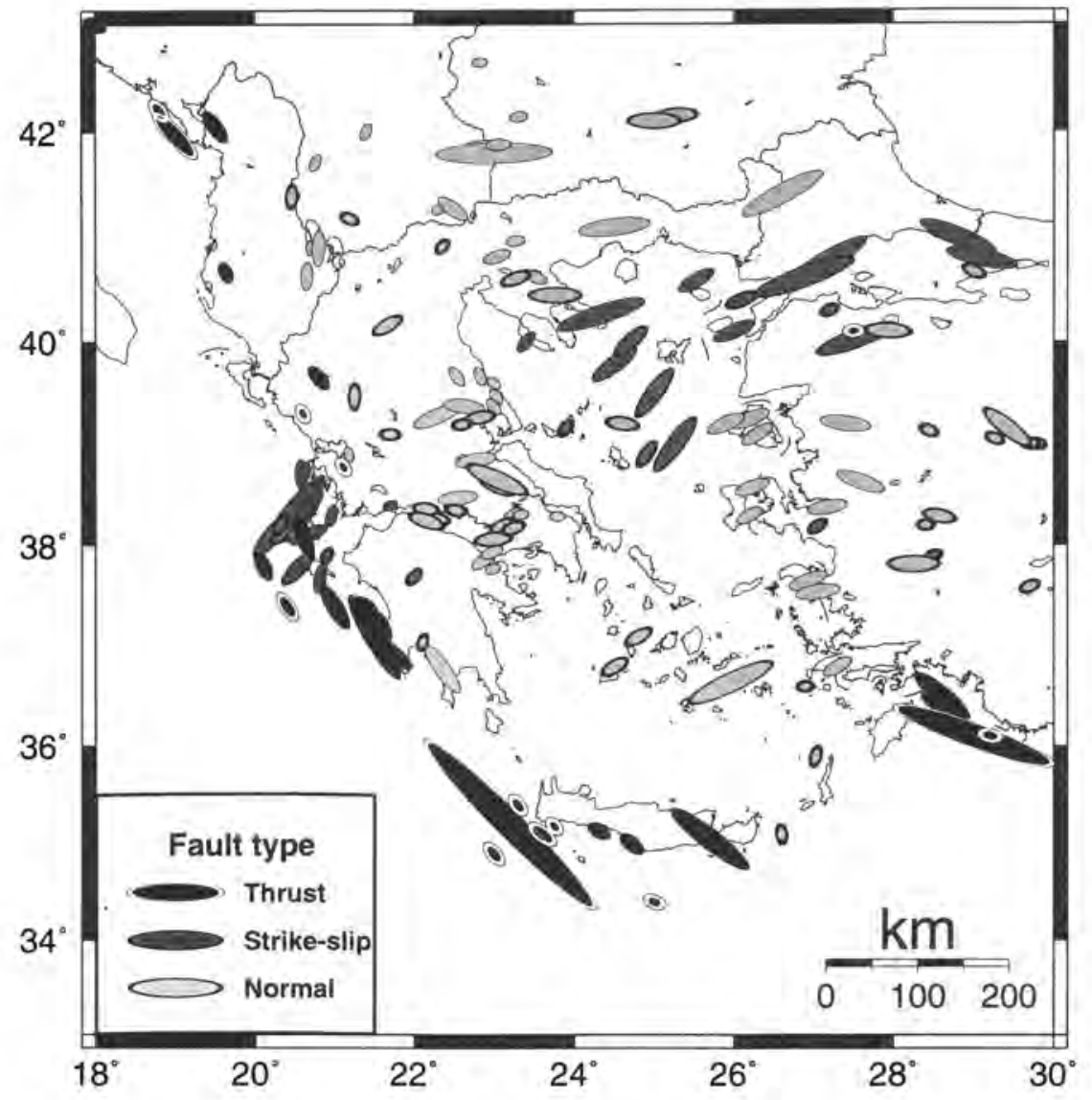

Figure 2. The rupture zones in the area of Greece [after Papazachos et al. 1999]. 
faulting, whereas north of Cephalonia, there is a zone of faults with dextral strike-slip faulting.

Figure 3 shows the space distribution of 278 earthquakes with magnitudes $\geq 4.5$ that occurred between January 1964 and December 2006. It can be seen that the focal depths of all of these shocks were $<50 \mathrm{~km}$, and that most of them were situated along the Hellenic Trench.

Tidal effects on a rigid Earth can be computed theoretically from the ephemerides of the Moon, the Sun and the planets. The Earth tides are the combined effects of these celestial bodies and the reactions of the solid Earth (like an elastic body) to the tidal forces. The ocean tides follow the law of hydrodynamics, with strong disturbances affecting

\begin{tabular}{ccccc}
\hline Symbol & $\begin{array}{c}\text { Period } \\
\mathrm{T}(\mathrm{min})\end{array}$ & $\begin{array}{c}\text { Signal/ } \\
\text { noise }\end{array}$ & $\begin{array}{c}\text { Amplitude } \\
\left(\mathrm{nms}^{-2}\right)\end{array}$ & Origin \\
\hline $\mathrm{K} 1$ & 1436 & 525.1 & 487.840 & Lunar and solar declination wave \\
$\mathrm{O} 1$ & 1549 & 379.7 & 352.816 & Lunar principal wave \\
$\mathrm{M} 2$ & 745 & 1208.5 & 510.350 & Lunar principal wave \\
$\mathrm{S} 2$ & 720 & 564.5 & 238.393 & Solar principal wave \\
\hline
\end{tabular}

Table 1. The strongest components of the Earth tides in Thessaloniki. adjacent seas, so that the ocean-loading effects have to be taken into account. Earth tides are discussed extensively in Melchior [1983], Baker [1984], Wilhelm et al. [1997], and Torge [2001].

The components of the Earth tides for the area of Thessaloniki were determined gravimetrically by Arabelos [2002]. Table 1 shows the strongest components of the Earth tides for Thessaloniki. Although the amplitude of the lunar tidal component M1 is $27.091 \mathrm{nms}^{-2}$ [see Arabelos 2002, Table 3], i.e. it is much weaker than the listed components, we consider in addition the possible effects of this component by means of the lunar synodic month (i.e. the period from new moon to new moon, which is 29.530589 days) and the lunar anomalistic month (i.e. the time period between two successive passes of the moon from perigee, which is 27.554551 days).

Table 2 shows the actual ocean corrected tidal parameters of $\mathrm{O} 1$ and $\mathrm{M} 2$ for Sofia, Instabul and Thessaloniki, and the corresponding values from the model of Wahr-Dehant-Zschau [Dehant 1987, Dehant and Zchau 1989], which expresses the dependency of the tidal parameters on latitude. As is shown from Table 2, the

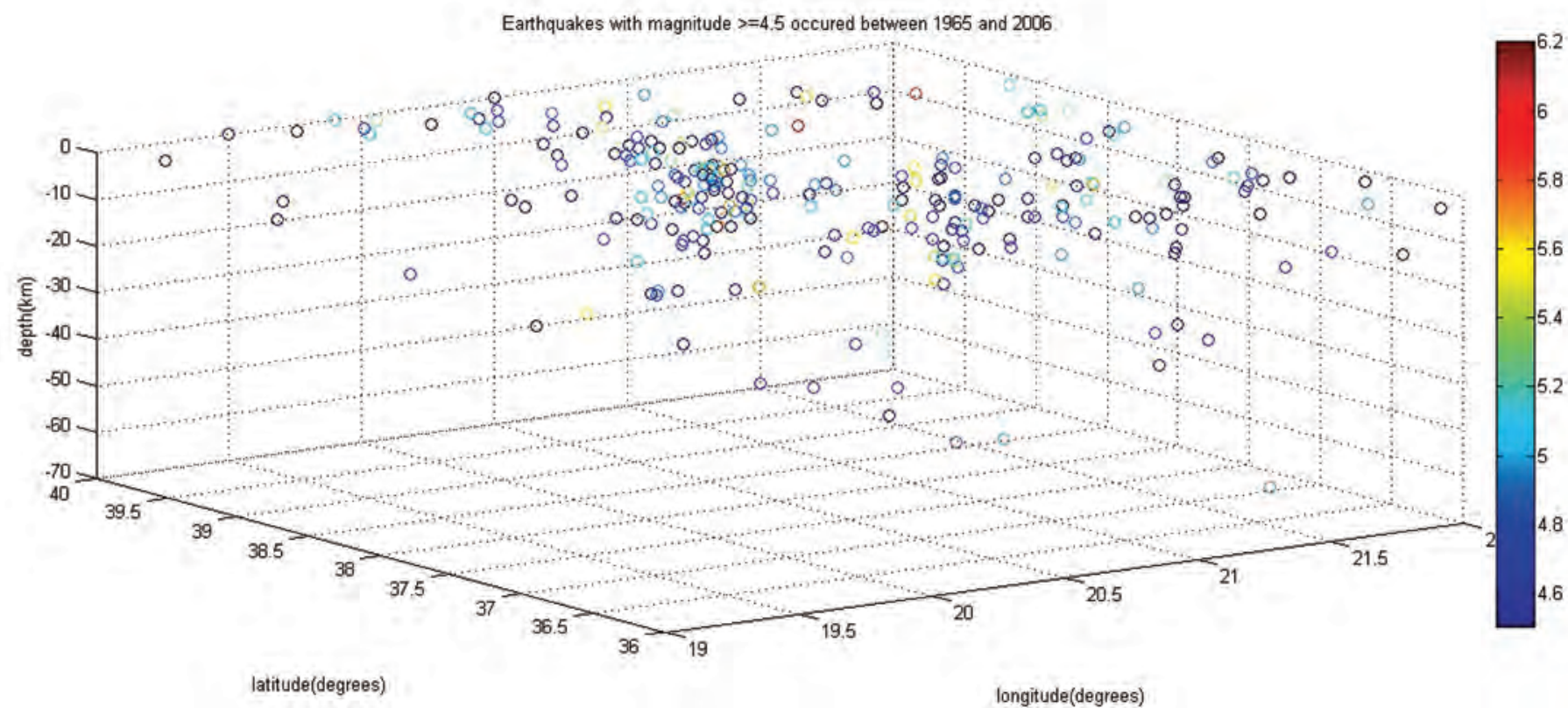

Figure 3. The space distribution of 278 earthquakes with magnitude $\geq 4.5$ that occurred in the period from January 1964 to December 2006 .

\begin{tabular}{|c|c|c|c|c|c|c|}
\hline \multirow[t]{2}{*}{ Parameter } & \multicolumn{2}{|c|}{$\begin{array}{c}\text { Sofia } \\
\text { (latitude } 42.71^{\circ} \text { ) }\end{array}$} & \multicolumn{2}{|c|}{$\begin{array}{c}\text { Istanbul } \\
\text { (latitude } 41.07^{\circ} \text { ) }\end{array}$} & \multicolumn{2}{|c|}{$\begin{array}{l}\text { Thessaloniki } \\
\text { (latitude } 40.63^{\circ} \text { ) }\end{array}$} \\
\hline & $\begin{array}{l}\text { Amplitude } \\
\text { factor }\end{array}$ & $\begin{array}{l}\text { Phase } \\
\text { degree }\end{array}$ & $\begin{array}{l}\text { Amplitude } \\
\text { factor }\end{array}$ & $\begin{array}{l}\text { Phase } \\
\text { degree }\end{array}$ & $\begin{array}{l}\text { Amplitude } \\
\text { nm factor }\end{array}$ & $\begin{array}{l}\text { Phase } \\
\text { degree }\end{array}$ \\
\hline O1 & $-1.1493 \pm 0.0014$ & $-0.1590 \pm 060$ & $1.1564 \pm 0.0035$ & $-0.281 \pm 0.174$ & $1.1536 \pm 0.003$ & $-0.201 \pm 0.151$ \\
\hline Model & 1.1540 & -0.2 & 1.1542 & -0.2 & 1.1543 & -0.2 \\
\hline M2 & $1.1541 \pm 0.0005$ & $-0.207 \pm 0.026$ & $1.1587 \pm 0.0011$ & $-0.039 \pm 0.026$ & $1.1639 \pm 0.001$ & $-0.195 \pm 0.001$ \\
\hline Model & 1.1541 & -0.2 & 1.1583 & -0.2 & 1.1583 & -0.2 \\
\hline
\end{tabular}

Table 2. Ocean corrected parameters of $\mathrm{O} 1$ and $\mathrm{M} 2$ in the three neighboring stations. 
amplitude factors of the principal $\mathrm{O} 1$ and M2 tidal components agree with the model, within their errors of estimation. For the latitude of $38^{\circ} \mathrm{N}$, which is the mean latitude of the area under consideration, the extrapolated model amplitude factors for O1 and M2 are 1.1545 and 1.1587, respectively. Consequently, the amplitudes of $\mathrm{O} 1$ and M2 might be changed to about $354 \mathrm{nms}-2$ and 501 $\mathrm{nms}^{-2}$, respectively, which are very close to the amplitudes observed in the tidal station of Thessaloniki. However, this estimation does not take into account the actual elastic properties of the lithosphere in the Ionian zone.

\section{Method of analysis}

To investigate the possible correlations between Earth tides and earthquake occurrence, we determined the time of occurrence of each earthquake in relation to the sinusoidal variation of the Earth tides, and investigated any possible correlations of the time distributions of these earthquake events with the Earth tide variations. Since the periods of the Earth tides component are very well known and relatively accurately predictable in the local coordination system, we assigned a unique phase angle within the period of variation of a particular tidal component for which the effect of earthquake triggering is under investigation, with the simple relationship:

$$
\phi_{i}=\left\{\left[\frac{\left(t_{i}-t_{0}\right)}{T_{d}}\right]-\operatorname{int}\left[\frac{\left(t_{i}-t_{0}\right)}{T_{d}}\right]\right\} \times 360,
$$

where $\phi$ is the phase angle of the time occurrence of the $i$ earthquake in degrees, $t_{i}$ is the time of occurrence of the $i$ earthquake in modified Julian days (MJD), $t_{0}$ is the period that we chose in MJD, and $T_{d}$ is the period of the particular tidal component in MJD.

We chose as epoch $t_{o}$, i.e. the reference date, the time of the upper culmination in Thessaloniki of the new moon of January 7, 1989, which was MJD 47533.8947453704. Thus the calculated phase angle for all of the periods under study has 0 phase angle at the maximum of the corresponding tidal component (M2 and $\mathrm{S} 2$ have an upper culmination maximum every two cycles). As far as the monthly anomalistic moon was

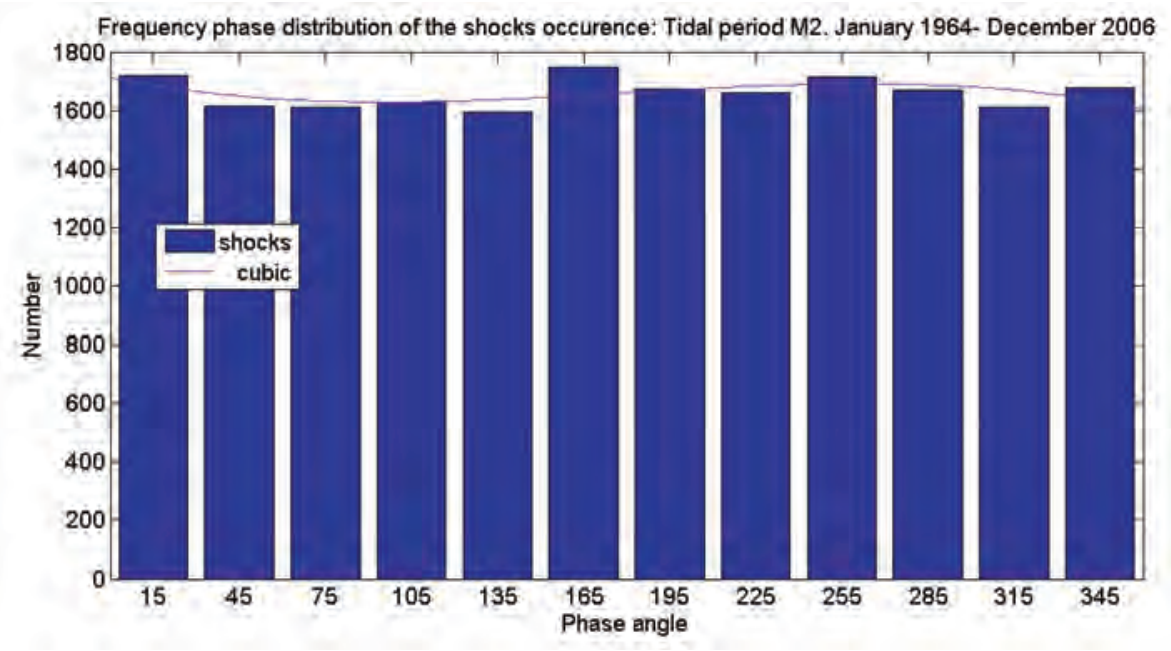

Figure 4. Cumulative histogram corresponding to the M2 period, of all of the 19.916 events.



Figure 5. Cumulative histogram corresponding to K1 period, of all of the 19.916 events. 
concerned, the corresponding epoch $t_{0}$ was January 14, 1989, which was MJD 47541.28492.

We separated the whole period into 12 bins of $30^{\circ}$ and stacked every event into the correct bin according to its phase angle. Thus, we constructed cumulative histograms of the earthquake events for the tidal period under study. For example, Figures 4 and 5 show the cumulative histograms for all of the 19.916 events in the area corresponding to the tidal frequencies of $\mathrm{K} 1$ and $\mathrm{M} 2$.

It appears that M2 affected the earthquake occurrence, with a phase lag of -90 and 0 degrees, while the $\mathrm{K} 1$ component affected the earthquake occurrence with a phase angle of +90 degrees. Are these data truth? A crucial point of this analysis is the use of a correct statistical test which will provide us with arguments upon which we can decide whether such a result is correct or not; i.e. will provide us with the correct confidence level for our decision. To this end, we used the well known Schuster's test [Schuster 1897, see also Tanaka et al. 2002, 2006, Cadicheanu et al. 2007]. In Schuster's test, each earthquake is represented by a unit length vector in the direction of the assigned phase angle $\alpha_{i}$. The vectorial sum $D$ is defined as:

$$
D^{2}=\left(\sum_{i=1}^{N} \cos a_{i}\right)^{2}+\left(\sum_{i=1}^{N} \sin a_{i}\right)^{2}
$$

where $N$ is the number of earthquakes. When $\alpha_{i}$ is distributed randomly, the probability for the length of a vectorial sum to be equal to or larger than $D$ is given by the equation:

$$
p=\exp \left(-D^{2} / N\right)
$$

Thus, $p<5 \%$ represents the significance level at which the null hypothesis that the earthquakes occurred randomly with respect to the tidal phase is rejected. This means that the smaller the $p$ is the greater the confidence level of the results of the cumulative histograms. For instance, from the abovepresented examples of Figures 4 and 5, it is apparent that the confidence level for the $\mathrm{K} 1$ tidal constituent to be a triggering mechanism of earthquakes in the area is very low; i.e. $p(\mathrm{~K} 1)=$ $82.21 \%$ while for the $\mathrm{M} 2$ constituent it is remarkably higher i.e. $p(\mathrm{M} 2)=25.64 \%$.



Figure 6. Cumulative histogram corresponding to the anomalistic month period, of all of the 19.916 events.

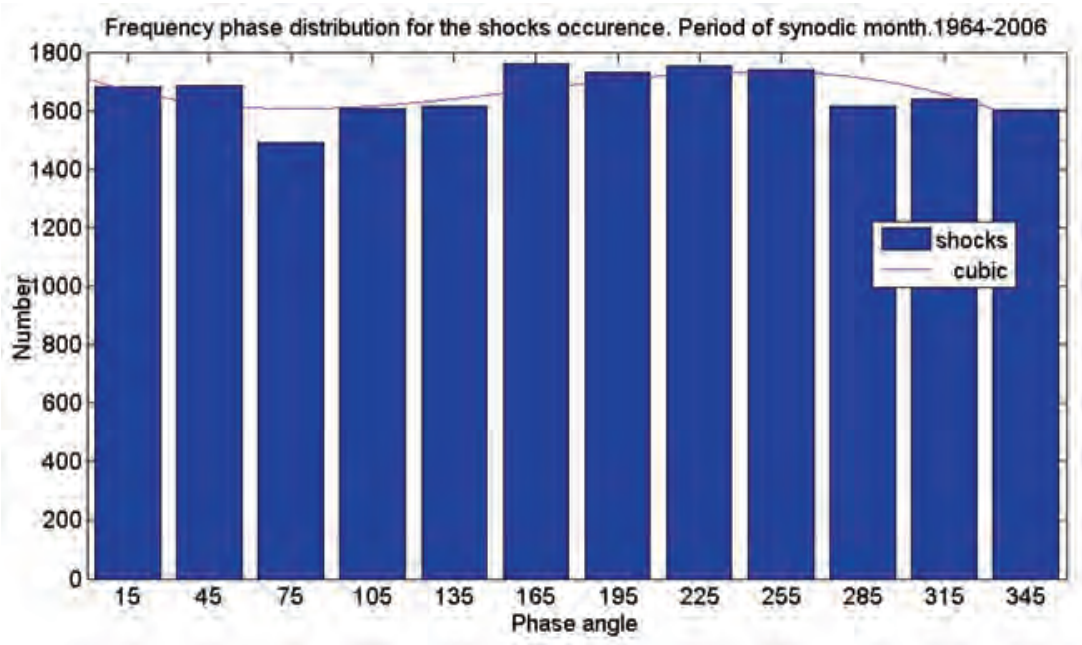

Figure 7. Cumulative histogram corresponding to the monthly synodic period, of all of the 19.916 events. 


\section{Results}

Figures 6 and 7 show the cumulative histograms for all of the 19.916 earthquakes with local magnitudes $>2.5$, which corresponds to the tidal periods of the lunar anomalistic (Figure 6; i.e. the period between two successive passages of the moon from perigee, which is 27.554551 days) and synodic (Figure 7; i.e. the period from new moon to new moon, which is 29.530589 days) month. Table 3 shows the corresponding confidence levels for all of the four tidal components.

\begin{tabular}{cccc}
\hline$p(\mathrm{~K} 1)$ & $p(\mathrm{M} 2)$ & $p$ (M anomalistic $)$ & $p$ (M synodic) \\
\hline $82.21 \%$ & $25.64 \%$ & $34.07 \%$ & $0.02 \%$ \\
\hline
\end{tabular}

Table 3. The confidence levels of the earthquake-Earth tide correlations for all the earthquakes in the present study.
It can be seen that the confidence levels for the lunar synodic month component to be responsible for the earthquake triggering mechanism is very high. The effects of the Lunar anomalistic month and Lunar semidiurnal M2 components are less probable, and the effects of the diurnal lunisolar component $\mathrm{K} 1$ are relatively improbable. Taking into account the low accuracy in the phase determination, due to the relatively large extent of the stacking bins (i.e. $30^{\circ}$ ), we can read the phase lags of the maximum seismic activity from Figures 6 and 7 , which are $+90^{\circ}$ and $+270^{\circ}$ for the anomalistic month, and $+30^{\circ}$ and $+210^{\circ}$ for the synodic month. Both of these follow the periodic variations of the maximal tidal forces, with different phase lags, but with a confidence level for a possible correlation between seismic activity and monthly tidal variation, which is much higher for the synodic month.
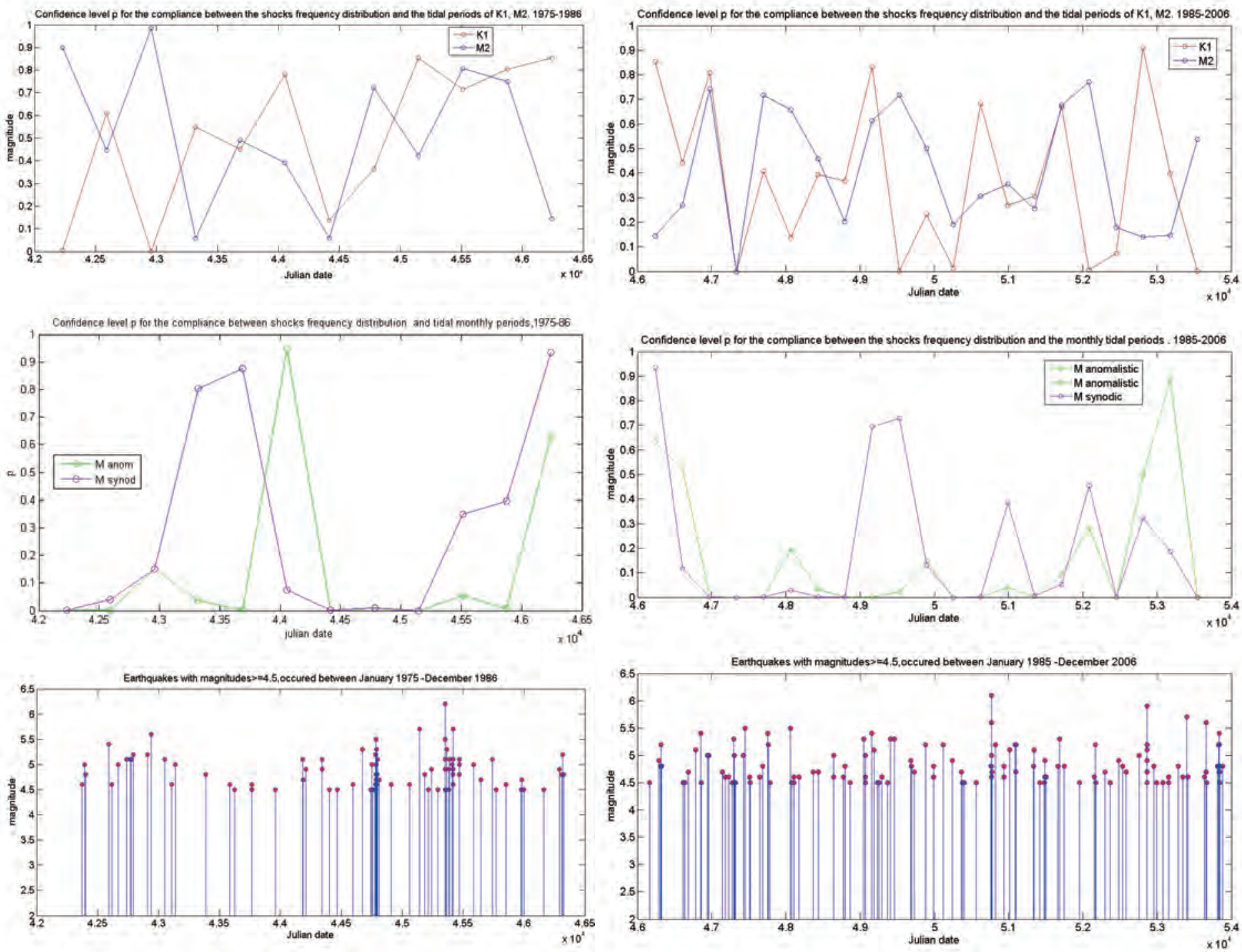

Figure 8 (left). Confidence levels for compliance between the frequency distribution of the shock occurrence and (a) K1, M2 tidal periods. (b) M-anomalistic and M-synodic periods. (c) Earthquakes with magnitudes $\geq 4.5$ for the time from January 1975 to December 1986.

Figure 9 (right). Confidence levels for compliance between the frequency distribution of the shock occurrence and (a) K1, M2 tidal periods. (b) Manomalistic and M-synodic periods. (c) Earthquakes with magnitudes $\geq 4.5$ for the time from January 1985 to December 2006. 
However the confidence level $p$ for the compliance of the frequency distribution for the shock occurrence with
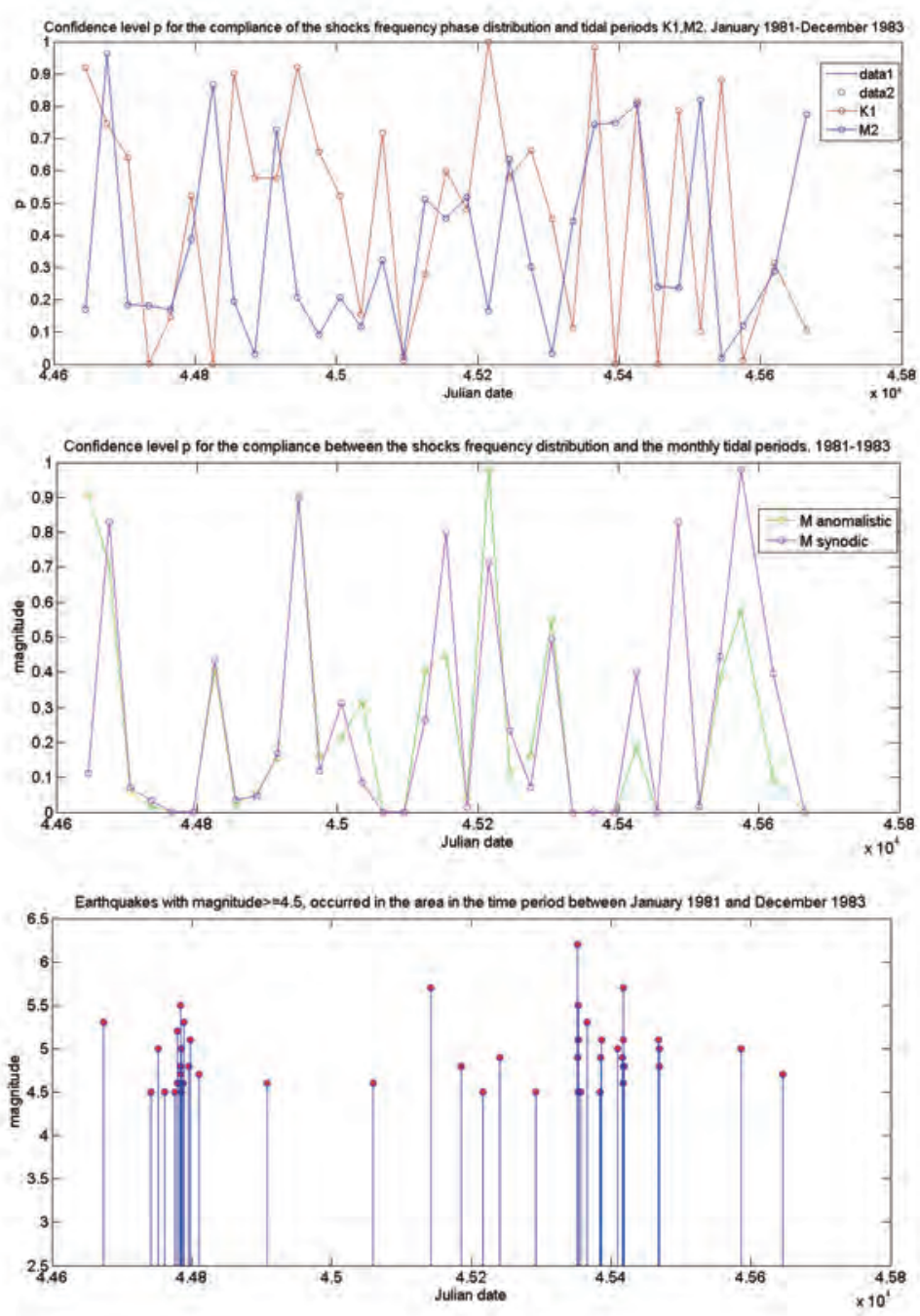

Figure 10. Confidence levels for compliance between the frequency distribution of the shock occurrence and (a) K1, M2 tidal periods. (b) Manomalistic and M-synodic periods. (c) Earthquakes with magnitudes $\geq 4.5$ for the time from January 1981 to December 1983. the tidal periods is not stable. It varies over the time, and it is smaller in periods of high seismic activity. This means that the confidence for the compliance of the frequency distribution for the shocks occurrence with the tidal periods is higher in the periods with increased seismic activity. This can be seen from Figures 8 and 9, where the yearly variations of $p$ together with the earthquakes with magnitudes $>4.5$ in the same period are shown, and it is more clearly evident from Figure 10, where the monthly variations of $p$ during the time period of increased seismic activity in the area of Zakynthos from January 1981 to December 1983 is shown.

From Figures 11, 12, 13 and 14, in conjunction with Table 4, it is apparent that there is good compliance of the frequency phase distribution of the shock occurrence with the K1, lunisolar tidal period, with medium compliance with the M2, semi-diurnal lunar period, and perfect compliance with M1, the monthly lunar anomalistic, and the synodic periods. The phase lags of all four of the frequency distributions are much the same as that of the total sample (see Figures 4, 5, 6 and 7), however, they are much more clearly seen. In particular, the phase lag for $\mathrm{K} 1$ is about $-90^{\circ}$, which is the phase of the maximum rate of change of the $\mathrm{K} 1$ tidal component, and about $+90^{\circ}$ and $0^{\circ}$ for $\mathrm{M} 2$, while the phase lags of the monthly M1 are $+30^{\circ}$ for the synodic, and $-90^{\circ}$ for the anomalistic. These result are in favour with the possibility that the combined gravitational tidal stress is an additional stress that triggers the earthquake event. The high compliance for the monthly tidal components despite their small intensities might indicate that in general they provide favourable conditions for the action of the much stronger tidal components $\mathrm{K} 1$ and M2. On this point, we can refer to the monthly tidal barometric variations that are quite sensitive to the seismic activity [Arabelos et al. 2008]. Perhaps this peculiar coincidence merits further investigation. Finally, we draw the attention to the confidence level $p$ for the

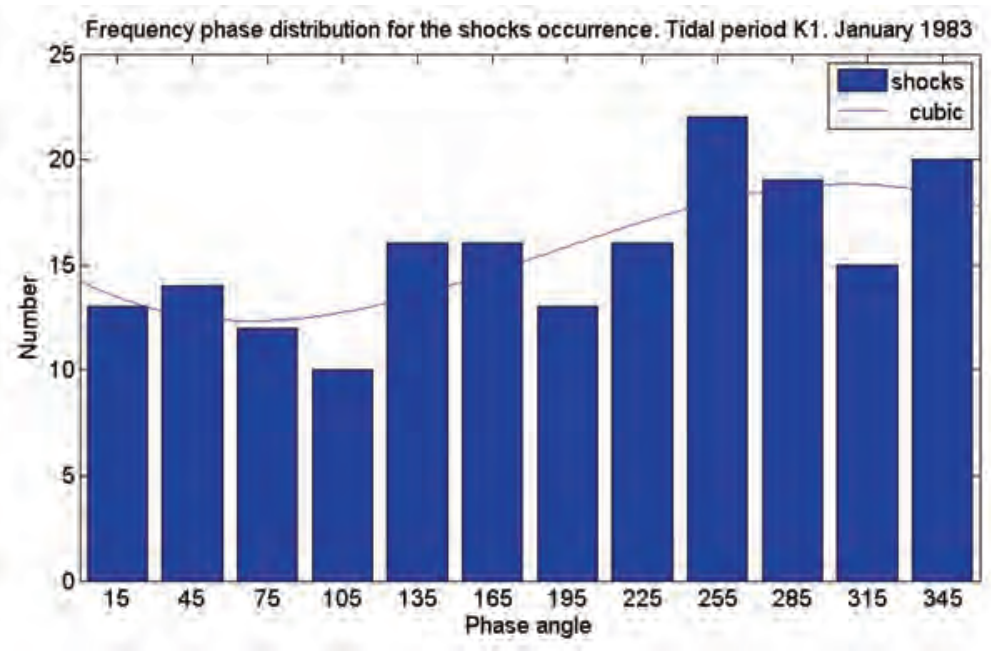

Figure 11. Cumulative histogram corresponding to the tidal period K1 of the 186 events that occurred during January 1983 in the area of Zakynthos. 


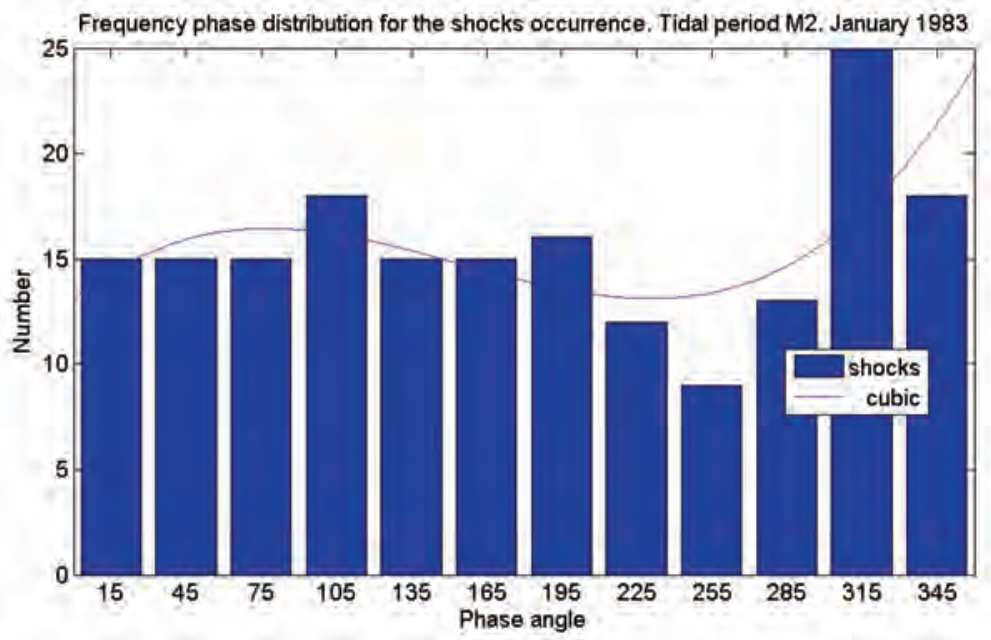

Figure 12. Cumulative histogram corresponding to the tidal period M2 of the 186 events that occurred during January 1983 in the area of Zakynthos.

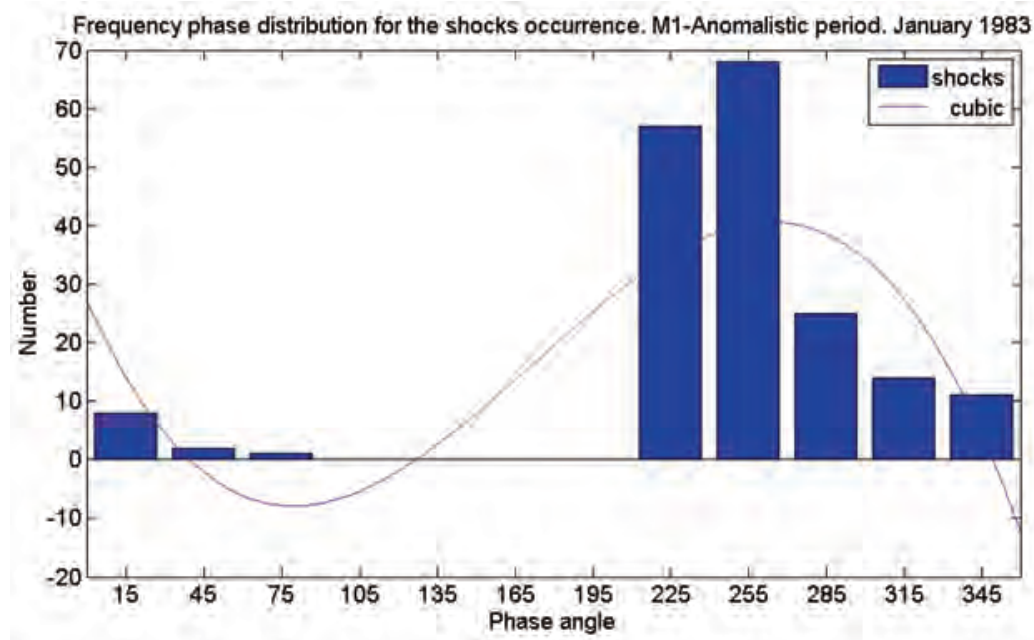

Figure 13. Cumulative histogram corresponding to the tidal period M1 anomalistic of the 186 events that occurred during January 1983 in the area of Zakynthos.

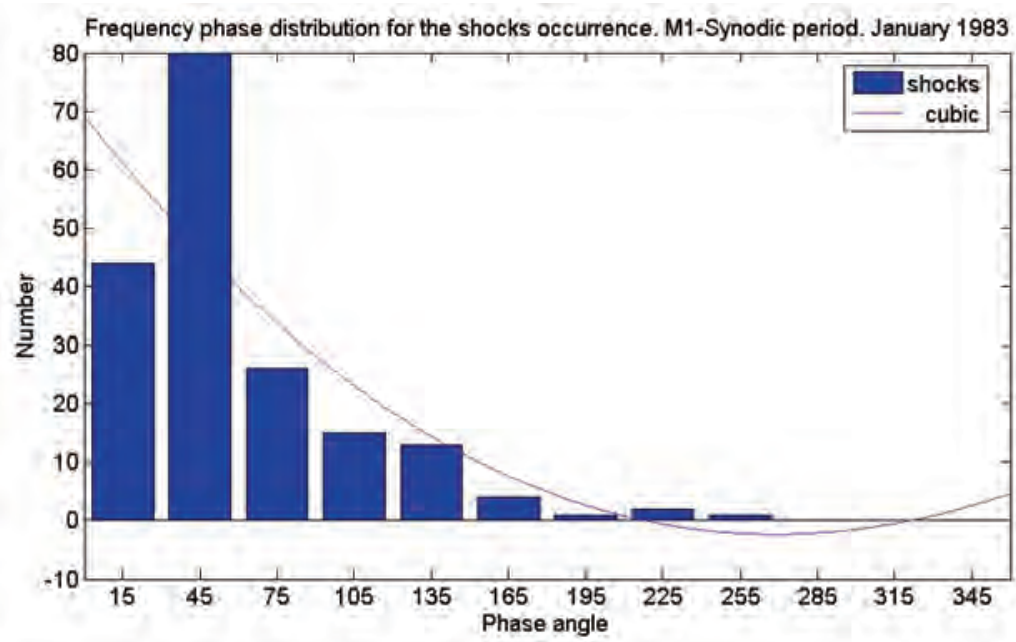

Figure 14. Cumulative histogram corresponding to the tidal period M1 synodic of the 186 events that occurred during January 1983 in the area of Zakynthos.

\begin{tabular}{cccc}
\hline$p(\mathrm{~K} 1)$ & $p(\mathrm{M} 2)$ & $p$ (M1- anomalistic $)$ & $p$ (M-synodic) \\
\hline $11.27 \%$ & $44.38 \%$ & $0.00 \%$ & $0.00 \%$ \\
\hline
\end{tabular}

Table 4. The confidence levels of the earthquake-earth tide correlation for the 186 earthquakes events that occurred during January 1983 in the area of Zakynthos. compliance of the frequency phase distribution of the shock occurrence, which increases around the time of high seismic activity. This indicates that the parameter $p$, which is a measure of this compliance, can be used as an additional earthquake precursory index. 


\section{Conclusions}

In the present study we investigated the tidal triggering evidence for the earthquakes of the seismic area of the Ionian geological zone in Greece. The results of our analysis using the cumulative histogram method indicate that the monthly variations in the frequencies of earthquake occurrence are in agreement with the period of the tidal lunar monthly $(\mathrm{Mm})$ variations. The same happens with the corresponding daily variations of the frequencies of earthquake occurrence, with the diurnal lunisolar (K1) and semidiurnal lunar (M2) tidal variations.

The statistical test of Schuster [1987] indicates very high probability for the monthly component $\mathrm{Mm}$ to act as a trigger mechanism for earthquake occurrence, and a small probability for the diurnal lunisolar $\mathrm{K} 1$ and semidiurnal lunar M2 components, although the variation amplitudes of both (K1, M2) are about 18 times greater than that of Mm. It appears that the revolution of the moon on its elliptical trajectory around the earth creates periodically favorable conditions for the triggering effect of the strong diurnal and semidiurnal components.

In addition, the confidence levels for the identification of such periodical agreement between earthquake occurrence frequencies and tidal periods varies with the seismic activity; i.e. the higher confidence levels correspond to periods with stronger seismic activity. These results are in favor of a tidal triggering process for earthquakes when the stress in the focal area is near the critical level. This indicates also that the parameter $p$, which is a measure of the confidence level, can be used as an additional earthquake precursory index.

\section{References}

Arabelos, D. (2002). Comparison of Earth-tide parameters over a large latitude difference, Geophys. J. Int., 151, 950956.

Arabelos, D.N., G. Asteriadis, A. Bloutsos, M.E. Contadakis and S.D. Spatalas (2008). Correlation between seismisity and barometric tidal exalting, Nat. Hazards Earth Syst., 8, 1129-1137.

Baker, T.F. (1984). Tidal determination of the Earth, Sci. Progr., 69, 197-233.

Cadicheanu, N., M. van Ruymbecke and P. Zhu (2007). Tidal triggering evidence of intermediate depth earthquakes in Vrancea zone (Romania), Nat. Hazards Earth Syst., 7, 733-740.

Dehant, V.( 1987). Tidal parameters for the inelastic Earth, Phys. Earth Planet. In., 49, 97-116.

Dehant, V. and J. Zschau (1989). The effect of mantle inelasticity on tidal gravity: a comparison between the spherical and the elliptical Earth model, Geophys. J., 97, 549-555.

Enescu, D. and B.D. Enescu (1999). Possible cause-effect re- lationships between Vrancea (Romania) earthquakes and some global geophysical phenomena, Nat. Hazards, 19, 233-245.

Knopoff, L. (1964). Earth tides as a triggering mechanism of earthquakes, Bull. Seismol. Soc. Am., 54, 1865-1870.

Melchior, P. (1983). The Tides of the Planet Earth, Pergamon Press, New York.

Papazachos, C., A. Kiratzi and D. Kontopoulou (1998). Active Tectonics in Aegean and Surrounding Area, In: Basic Results of the Seismologic in Greece, Honorem Prof. B.C. Papazachos, Ziti Publication, Thessaloniki, 49-74 Greece (in Greek).

Papazachos, B.C., C.A. Papaioannou, C.B. Papazachos and A.S. Savvaidis (1999). Rupture zones in the Aegean region, Tectonophysics, 308, 205-221.

Rydelek, P.A., I.S. Sacks and R. Scarpa (1992). On tidal triggering of earthquakes at Campi Flegrei, Italy, Geophys. J. Int., 109, 125-137.

Schuster, A. (1897). On lunar and solar periodicities of earthquakes, P. Roy. Soc. Lond., 61, 455-465.

Shudde, R.H. and D.R. Barr (1977). An analysis of earthquake frequency data, Bull. Seismol. Soc. Am., 67, 1379-1386.

Simpson, J.F. (1967). Earth tides as a triggering mechanism for earthquakes, Earth Planet Sci. Lett., 2, 473-478.

Stavinschi, M. and J. Souchay (2003). Some correlations between earthquakes and Earth tides, Acta Geod. Geoph. Hung., 38, 77-92.

Tanaka, S., M. Ohtake and H. Sato, (2002). Evidence for tidal triggering of earthquakes as revealed from statistical analysis of global data, J. Geophys. Res., 107, 2211.

Tanaka, S., S. Sato, H. Matsumura and M. Ohtake (2006). Tidal triggering of earthquakes in the subducting Philipine Sea plate beneath the locked zone of the plate interface in Tokai region, Japan, Tectonopysics, 417, 69-80.

Torge, W. (2001). Geodesy, 3rd Edition, Walter de Gruyter, Berlin-New York.

Vidale, J.E., D.C. Agnew, M.J.S. Johnston and D.H. Oppenheimer (1998). Absence of earthquake correlation with earth tides: an indication of high preseismic fault stress rate, J. Geophys. Res., 103, 24567-24572.

Wilhelm, H., W. Zürn, H-G. Wenzel (Eds.) (1997). Tidal phenomena, Springer, Berlin-Heidelberg-New York.

\footnotetext{
^Corresponding author: Michael E. Contadakis, Aristotle University of Thessaloniki, Department of Geodesy and Surveying, Thessaloniki, Greece; email:kodadaki@eng.auth.gr.
}

(C) 2012 by the Istituto Nazionale di Geofisica e Vulcanologia. All rights reserved. 